\title{
A FILOSOFIA FRANCESA ${ }^{1}$
}

\section{Henri Bergson}

Tradução: Silene Torres MARQUES ${ }^{2}$

\section{I}

O papel da França na evolução da filosofia moderna é bastante claro: a França foi a grande iniciadora. Em outros lugares sugiram igualmente, sem dúvida, filósofos de gênio; mas em nenhuma parte, houve, como na França, continuidade ininterrupta de criação filosófica original. Em outros lugares pôde-se ir mais longe no desenvolvimento de uma ou outra idéia, construir mais sistematicamente com um ou outro material, dar mais extensão a um ou outro método; mas com muita freqüencia, os materiais, as idéias, o método tinham vindo da França. Não se trata aqui de enumerar todas as doutrinas, nem de citar todos os nomes. Faremos uma escolha; depois, trataremos de distinguir os traços característicos do pensamento filosófico francês. Veremos porque ele permaneceu criador, e a que se deve sua potência de irradiação.

1 Aparecido originalmente em 1915, na Revista de Paris (pp.236-356), este texto de Bergson é um texto de divulgação. Destinado à Exposição universal e internacional de São Francisco, de 1915 ele faz uma recapitulação dos principais representantes da filosofia francesa, mostrando suas principais contribuições ou influências, em diversas áreas do conhecimento, do século XVII até o início do século XX. Em sua versão original era introduzido por uma nota com o seguinte texto: "Este trabalho deve ser distribuído, na forma de brochura, aos visitantes da Exposição de São Francisco. Com outros trabalhos do mesmo gênero, dirigindo-se aos diferentes ramos da ciência, e redigidos por diversos autores, ele fará parte de uma obra intitulada A Ciência francesa, que aparecerá brevemente na Livraria Larousse". Há ainda uma outra versão, escrita em 1933, que tem por base o texto de 1915, mas recebe a colaboração do filósofo bergsoniano Edouard Le Roy; é a que aparece no volume Mélanges (pp.1157-89). [N.T.]

2 Professora Adjunto do Departamento de Filosofia e Metodologia das Ciências e do Programa de Pós-Graduação em Filosofia da Universidade Federal de São Carlos-UFSCar. Tradução recebida em jan/06 e aprovada para publicação em nov/06. 
Toda a filosofia moderna deriva de Descartes (1596-1650). Não tentaremos resumir sua doutrina: cada progresso da ciência e da filosofia permite descobrir nela algo de novo, de modo que compararíamos facilmente esta obra às obras da natureza, cuja análise jamais será terminada. Mas, assim como o anatomista faz em um órgão ou em um tecido uma série de cortes que ele estuda sucessivamente, nós iremos recortar a obra de Descartes em planos paralelos situados uns abaixo dos outros, para obter dela, sucessivamente, visões cada vez mais profundas.

Um primeiro recorte revela no cartesianismo a filosofia das idéias "claras e distintas", a que definitivamente libertou o pensamento moderno do jugo da autoridade para não admitir outra marca da verdade senão a da evidência.

Um pouco mais em baixo, cruzando a significação dos termos "evidência", "clareza", "distinção", encontramos uma teoria do método. Descartes, inventando uma nova geometria, analisou o ato de criação matemática. Ele descreve as condições desta criação. Ele fornece assim os procedimentos gerais de pesquisa, que lhe foram sugeridos por sua geometria.

Aprofundando por sua vez esta extensão da geometria, chegaremos a uma teoria geral da natureza, considerada como um imenso mecanismo regido por leis matemáticas. Descartes forneceu então à física moderna seu quadro, o plano sobre o qual ela jamais cessou de trabalhar, ao mesmo tempo que forneceu o modelo de toda concepção mecânica do universo.

Abaixo desta filosofia da natureza encontraríamos agora uma teoria do espírito ou, como diz Descartes, do "pensamento", um esforço para resolver o pensamento em elementos simples: este esforço abriu caminho às pesquisas de Locke e de Condillac. Encontraríamos sobretudo esta idéia que o pensamento existe primeiro, que a matéria é dada por acréscimo e poderia, a rigor, existir apenas como representação do espírito. Todo o idealismo moderno saiu daí, em particular o idealismo alemão.

Enfim, no fundo da teoria cartesiana do pensamento há um novo esforço para reconduzir o pensamento, ao menos parcialmente, à vontade. As filosofias "voluntaristas" do século XIX vinculam-se deste modo, a Descartes. Não é sem razão que se viu no cartesianismo uma "filosofia da liberdade".

A Descartes remontam, portanto, as principais doutrinas da filosofia moderna. De outra parte, embora o cartesianismo ofereça semelhanças de detalhe com uma ou outra doutrina da antiguidade ou da idade média, ele não deve nada de essencial a nenhuma delas. O matemático e físico Biot afirmou da geometria de Descartes: "proles sine matre creata". Nós diríamos o mesmo de sua filosofia.

Se todas as tendências da filosofia moderna coexistem em Descartes, é o racionalismo que predomina, como devia dominar o pensamento dos sé- 
culos seguintes. Mas ao lado, ou antes, abaixo da tendência racionalista, recoberto e freqüentemente dissimulado por ela, há uma outra corrente que atravessa a filosofia moderna. É a que se poderia chamar sentimental, com a condição de tomar a palavra "sentimento" na acepção que lhe dava o século XVII e aí compreender todo conhecimento imediato e intuitivo. Ora, esta Segunda corrente deriva, como a primeira, de um filósofo francês. Pascal (1623-1662) introduziu em filosofia uma certa maneira de pensar que não é a pura razão, pois ela corrige pelo "espírito de finura" o que o raciocínio tem de geométrico, e que não é tampouco a contemplação mística, uma vez que ela chega a resultados suscetíveis de ser controlados e verificados por todo mundo. Encontraríamos, re-estabelecendo os anéis intermediários da cadeia, que a Pascal se vinculam as doutrinas modernas que colocam em primeiro plano o conhecimento imediato, a intuição, a vida interior, como a Descartes (apesar das veleidades de intuição que encontramos no próprio cartesianismo) se vinculam, mais particularmente as filosofias da razão pura. Não podemos empreender este trabalho. Limitemo-nos a constatar que Descartes e Pascal são os grandes representantes das duas formas ou métodos de pensamento entre as quais se divide o espírito moderno.

Um e outro romperam com a metafísica dos Gregos. Mas o espírito humano não renuncia facilmente àquilo que ele transformou em seu alimento durante muitos séculos. A filosofia grega havia alimentado a idade média, graças a Aristóteles. Ela havia impregnado a Renascença, graças, sobretudo a Platão. Era natural que procurássemos, após Descartes, utilizá-la aproximando-a do cartesianismo. Devíamos ser aí conduzidos pela própria tendência dos filósofos a colocar seu pensamento sob uma forma sistemática, pois o "sistema" por excelência é o que foi, preparado por Platão e Aristóteles, definitivamente constituído e consolidado pelos neo-platônicos; e seria fácil mostrar (não podemos entrar no detalhe desta demonstração) que toda tentativa para erigir/construir um sistema se inspira por algum lado no aristotelismo, no platonismo ou no neo-platonismo. De fato, as duas doutrinas metafísicas que surgiram fora da França na segunda metade do século XVII foram combinações do cartesianismo com a filosofia grega. A filosofia de Espinosa, tão original que é, termina por fundir a metafísica de Descartes e o aristotelismo dos doutores judeus. A de Leibniz, da qual não ignoramos tampouco a originalidade, é ainda uma combinação do cartesianismo com o aristotelismo, sobretudo com o aristotelismo dos neo-platônicos. Por razões que indicaremos a seguir, a filosofia francesa nunca teve muito gosto pelas grandes construções metafísicas; mas quando chegou a empreender especulações deste gênero, mostrou o que era capaz de fazer, e com qual facilidade o fazia. Enquanto Espinosa e Leibniz construíam seu sistema, Malebranche (1638-1715) havia construído o seu. Ele também havia combinado o cartesianismo com a metafísica dos Gregos (mais particularmente 
com o platonismo dos Padres da Igreja). O monumento que ele erigiu é um modelo do gênero. Mas há ao mesmo tempo em Malebranche toda uma psicologia e toda uma moral que conservam seu valor, mesmo se não aderimos à sua metafísica. Esta é uma das marcas da filosofia francesa: se ela consente às vezes em tornar-se sistemática, ela não se resigna ao espírito de sistema; ela não deforma a tal ponto os elementos da realidade que não possamos utilizar os materiais da construção fora da própria construção. Os fragmentos estão sempre bons.

Descartes, Pascal, Malebranche, tais são os três grandes representantes da filosofia francesa no século XVII. Eles forneceram três tipos de doutrinas que encontramos nos tempos modernos.

Essencialmente criadora foi ainda a filosofia francesa do século XVIII. Mas, aqui ainda, devemos renunciar a entrar no detalhe. Digamos uma palavra das teorias mais importantes e citemos os principais nomes.

Apenas se começa a restituir a Lamarck (1744-1829) o reconhecimento que lhe é devido. Este naturalista que foi também filósofo é o verdadeiro criador do evolucionismo biológico. Ele é o primeiro que concebeu nitidamente, e levou até o fim, a idéia de fazer sair as espécies umas das outras por meio de transformação. A glória de Darwin não é por isto diminuída. Darwin estudou mais de perto os fatos; ele descobriu, sobretudo, o papel da competição e da seleção. Mas competição e seleção explicam como certas variaÇões se conservam; elas não dão conta - Darwin mesmo dizia - das causas da variação. Bem antes de Darwin - pois suas pesquisas datam do fim do século XVIII e do começo do XIX - Lamarck havia afirmado com a mesma nitidez a transformação das espécies, e ele havia tentado, além disto, determinar suas causas. Vários naturalistas hoje retornam a Lamarck, seja para combinar conjuntamente lamarckismo e darwinismo, seja mesmo para substituir o darwinismo por um lamarckismo melhorado. Quer dizer que a França forneceu à ciência e à filosofia, - ao século XVIII, - o grande princípio de explicação do mundo organizado, como, ao século precedente, com Descartes, ela lhe havia dado o plano de explicação da natureza inorgânica. As pesquisas e as reflexões de Lamarck haviam sido, aliás, preparadas na França por muitos trabalhos originais sobre a natureza e a vida. Limitemo-nos a relembrar os nomes de Buffon (1707-1788) e de Bonnet (1720-1793). ${ }^{3}$

De uma maneira geral, os pensadores franceses do século XVIII forneceram os elementos de certas teorias da natureza que deviam se constituir no século seguinte. Acabamos de falar do problema da origem das espécies.

3 Charles Bonnet, nascido em Genebra, pertencia a uma família francesa. 
O da relação do espírito com a matéria, abordado num sentido preferencialmente materialista, foi colocado entretanto pelos filósofos franceses do século XVIII com uma tal precisão que ele exigia igualmente, desde então, outras soluções. É preciso citar aqui os nomes de La Mettrie (1709-1751), Cabanis (1757-1808), etc, e ainda o de Charles Bonnet.

Mostraríamos sem dificuldade que suas pesquisas estão na origem da psico-fisiologia que foi desenvolvida durante o século XIX. Mas a própria psicologia, entendida como ideologia, ou seja, como reconstrução do espírito com elementos simples, - a psicologia tal como a compreendeu a escola "associacionista" do século anterior, - saiu, em parte, dos trabalhos franceses do século XVIII, notadamente dos de Condillac. É justo reconhecer que os Ingleses aí contribuíram com uma parcela ainda maior, e que a doutrina de Locke exerceu alguma influência sobre a ideologia francesa. Mas Locke não havia sido, ele mesmo, influenciado por Descartes? Antecipando sobre o que diremos do século XIX, podemos desde agora fazer observar que a obra psicológica de Taine, sua análise da inteligência, deriva em parte da ideologia do século XVIII, mais especialmente de Condillac.

Não temos que fazer aqui da filosofia social. Todo mundo sabe como se elaboraram na França, no decorrer do século XVIII, os princípios da ciência política em geral, e mais particularmente as idéias que deviam ocasionar uma transformação da sociedade. É devido a Montesquieu (1689-1755), a Turgot (1727-1781), a Condorcet (1713-1794), o aprofundamento dos conceitos de lei, de governo, de progresso, etc, como aos enciclopedistas em geral (d'Alembert (1717-1783), Diderot (1713-1781), La Mettrie (1709-1751), Helvetius (1715-1771), d'Holbach (1723-1789)) o movimento que desembocou na "racionalização" da humanidade e também na sua conversão para o lado das artes mecânicas.

Mas a mais potente das influências exercidas sobre o espírito humano desde Descartes, - de qualquer maneira aliás, que a julguemos, - é incontestavelmente a de Jean-Jacques Rousseau (1712-1778). ${ }^{4}$ A reforma que ele operou no domínio do pensamento prático foi tão radical quanto havia sido a de Descartes no domínio da especulação pura. Ele também recoloca tudo em questão; ele quis remodelar a sociedade, a moral, a educação, a vida inteira do homem sobre princípios "naturais". Aqueles mesmos que não aderiram a suas idéias tiveram que adotar alguma coisa de seu método. Pelo apelo que ele lançou ao sentimento, à intuição, à consciência profunda, ele encorajou uma certa maneira de pensar que encontrávamos já em Pascal (dirigida, é verdade, num sentido bem diferente), mas que não havia ainda direito de cidadania em filosofia. Embora não tenha construído um sistema,

4 Nascido em Genebra, de uma família de origem francesa. 
ele inspirou em parte os sistemas metafísicos do século XIX: o kantismo inicialmente, depois o "romantismo" da filosofia alemã lhe devem muito. A arte e a literatura lhe devem ao menos o mesmo tanto. Sua obra aparece a cada nova geração sob algum novo aspecto. Ela age ainda sobre nós. ${ }^{5}$

No breve olhar que acabamos de lançar sobre a filosofia francesa dos séculos XVII e XVIII, nós consideramos uma visão do conjunto; tivemos que deixar de lado grande número de pensadores e considerar apenas os mais importantes dentre eles. E quanto ao século XIX? Quase não há sábio francês, nem mesmo escritor francês, que não tenha dado sua contribuição à filosofia. Se os três séculos precedentes viram nascer e se desenvolver as ciências abstratas e concretas da matéria inorgânica, - matemáticas, mecânica, astronomia, física e química, - o século XIX devia aprofundar ainda mais as ciências da vida: vida orgânica e mesmo, até um certo ponto, vida social. Aqui ainda os Franceses foram os iniciadores. Devemos a eles a teoria do método, e uma parte importante dos resultados. Fazemos alusão, sobretudo a Claude Bernard, e a Auguste Comte.

A introdução à medicina experimental de Claude Bernard (1813-1878) foi, para as ciências concretas de laboratório, o que o Discurso do método de Descartes havia sido para as ciências mais abstratas. É a obra de um fisiologista de gênio que se interroga sobre o método que seguiu, e que tira de sua própria experiência regras gerais de experimentação e de descoberta. A pesquisa científica, tal como Claude Bernard a recomenda, é um diálogo entre o homem e a natureza. As respostas que a natureza fornece às nossas questões dão ao diálogo um aspecto imprevisto, provocam novas questões às quais a natureza replica sugerindo novas idéias, e assim segue indefinidamente. Nem os fatos nem as idéias são assim constitutivos da ciência: esta, sempre provisória e sempre, em parte, simbólica, nasce da colaboração da idéia e do fato. Imanente à obra de Claude Bernard está, deste modo, a afirmação de um desvio entre a lógica do homem e a da natureza. Sobre este ponto, e sobre vários outros, Claude Bernard ultrapassou os teóricos "pragmatistas" da ciência.

O Curso de filosofia positiva de Auguste Comte (1798-1857) é uma das grandes obras da filosofia moderna. A idéia, simples e genial, de estabelecer entre as ciências uma ordem hierárquica que vai das matemáticas à sociologia, ${ }^{6}$ se impôs em nosso espírito, desde que Comte a formulou, com a

5 Voltaire (1691-1778) pertence mais à história das letras que à da filosofia. Nós nos interessamos sobretudo, no presente trabalho, por aqueles que foram, em filosofia, criadores de idéias e de métodos novos.

6 A sociologia devendo ser objeto de uma monografia especial, não falamos aqui nem de Saint-Simon, nem de Fourier, nem de Pierre Leroux, nem de Proudhon. A mesma razão faz que deixemos 
força de uma verdade definitiva. Se podemos contestar sobre certos pontos a obra sociológica do mestre, ele entretanto teve o mérito de traçar à sociologia seu programa e de começar a completá-lo. Reformador à maneira de Sócrates, ele teria estado inteiramente disposto, como se assinalou, a adotar a máxima socrática "conhece-te a ti mesmo"; mas ele a teria aplicado às sociedades e não mais aos indivíduos, o conhecimento do homem social sendo a seus olhos o ponto culminante da ciência e o objeto por excelência da filosofia. Acrescentemos que o fundador do positivismo, que se declarou o adversário de toda metafísica, é uma alma de metafísico, e que a posteridade verá em sua obra um potente esforço para "divinizar" a humanidade.

Renan (1823-1892) não tem parentesco intelectual com Comte. Mas, à sua maneira, e num sentido bastante diferente, teve, ele também, esta religião da humanidade que havia sonhado o fundador do positivismo. A sedução que ele exerceu sobre seu tempo se deve a muitas causas. Primeiramente, ele foi um maravilhoso escritor, se, no entanto, ainda podemos chamar escritor, aquele que nos faz esquecer que ele emprega palavras, seu pensamento parecendo insinuar-se diretamente no nosso. Mas muito sedutora também, bem adaptada ao século que havia revificado as ciências históricas, era a concepção duplamente otimista da história que penetrava a obra deste mestre; pois, de uma parte, ele pensava que a história registra um progresso ininterrupto da humanidade, e, de outra parte, ele via nela um sucedâneo da filosofia e da religião.

Esta mesma fé na ciência - nas ciências que estudam o homem - se encontra em Taine (1828-1893), um pensador que teve a mesma influência que Renan na França, e talvez mais ainda que Renan no estrangeiro. Taine quis aplicar ao estudo da atividade humana, sob suas diversas formas, na literatura, na arte, na história, os métodos do naturalista e do físico. De outra parte, ele é todo penetrado pelo pensamento dos mestres antigos; com Espinosa ele acreditava na necessidade universal; sobre a potência de algum modo mágica da abstração, sobre as "qualidades principais" e as "faculdades superiores", ele tem visões que o aproximam de Aristóteles e de Platão. Ele retorna assim, implicitamente, à metafísica; mas ele limita o horizonte desta metafísica ao homem e às coisas humanas. Não mais que Renan, ele não se parece nem se vincula a Comte. E, no entanto, não é completamente sem razão que o classificamos às vezes, assim como o próprio

de lado pensadores contemporâneoas eminentes que se orientaram para a sociologia: Espinas, Tarde, Durkheim, Lévy-Brühl, Le Bon, Worms, Bouglé, Simiand, Izoulet, Lacombe, Richard e muitos outros. A obra da escola sociológica francesa é considerável; é preciso que ela seja estudada separadamente. A ela vincularíamos a obra dos moralistas: Bureau, Belot, Parodi, H. Michel, Caro, Bourdeau, Rauh, Darlu, Malapert, Buisson, etc Enfim, seria preciso conceder um lugar à partepois ele não se enquadra em nenhuma categoria - ao pensador original que é G. Sorel. 
Renan, entre os positivistas. Há muitas maneiras, com efeito, de definir o positivismo: mas cremos que é preciso ver aí, antes de tudo, uma concepção antropocêntrica do universo.

Entre a filosofia biológica e a filosofia social, cuja criação é devida em grande parte ao gênio francês, vem se colocar uma série de pesquisas que, também, pertencem sobretudo ao século XIX: queremos falar da psicologia. Isto não quer dizer que não houve ou tenha havido, particularmente na França, na Inglaterra e na Escócia, psicólogos penetrantes; mas a observação interior, deixada a si mesma e reduzida ao estudo dos fenômenos normais, tinha dificilmente acesso a certas regiões do espírito, notadamente ao "subconsciente". Ao método habitual de observação interior o século XIX acrescentou outros dois: de um lado, o conjunto dos procedimentos de mensuração do qual fazemos uso nos laboratórios, e, de outra parte, o método que poderíamos chamar clínico, o que consiste em recolher observações de doenças e mesmo provocar fenômenos mórbidos (intoxicação, hipnotismo, etc). Destes dois métodos, o primeiro foi praticado, sobretudo na Alemanha; embora ele não seja negligenciável, ele está longe de ter dado o que se esperava dele. ${ }^{7}$ O segundo, ao contrário, já forneceu resultados importantes, e ele deixa entrever outros, ainda mais consideráveis. Ora, esta segunda psicologia, hoje cultivada em muitos países, é uma ciência de origem francesa, que permaneceu eminentemente francesa. Preparada pelos alienistas franceses da primeira metade do século XIX, ela se constituiu de uma maneira definitiva com Moreau de Tours, e ela não cessou, depois, de ser representada na França por mestres, sejam eles vindos da patologia para a psicologia, sejam eles psicólogos atraídos pela patologia mental. Bastar-nos-á citar os nomes de Charcot, Ribot, Pierre Janet e Georges Dumas.

Mas, enquanto uma parte da filosofia francesa, no século XIX, orientava-se assim na direção da fisiologia, da psicologia, da sociologia, o resto tomava por objeto de especulação, como nos séculos precedentes, a natureza em geral, o espírito em geral.

Desde o início do século, a França teve um grande metafísico, o maior que ela produziu desde Descartes e Malebranche: Maine de Biran (17661824). ${ }^{8}$ Pouco notada no momento em que apareceu, a doutrina de Maine de

7 Ele teve, na França, representantes notáveis. Citemos em particular Alfred Binet.

8 De Biran seria preciso aproximar Ampère (1775-1826). Não há lugar aqui para falar da escola teológica. Lembremos os nomes de De Bonald (1754-1840), de De Maistre (1753-1821) e de Lamennais (1782-1854). 
Biran exerceu uma influência crescente: podemos perguntar se a via que este filósofo abriu não é aquela na qual a metafísica deverá caminhar definitivamente. Ao contrário de Kant (pois é injustamente que foi chamado o "Kant francês"), Maine de Biran julgou que o espírito humano era capaz, ao menos sobre um ponto, de atingir o absoluto e fazer dele o objeto de suas especulações. Ele mostrou que o conhecimento que temos de nós mesmos, em particular no sentimento do esforço, é um conhecimento privilegiado, que ultrapassa o puro "fenômeno" e que atinge a realidade "em si", - esta realidade que Kant declarava inacessível às nossas especulações. Enfim, ele concebeu a idéia de uma metafísica que se elevaria cada vez mais alto, em direção ao espírito em geral, na medida em que a consciência desceria mais baixo, nas profundezas da vida interior. Visão genial, da qual ele tirou as conseqüências sem se perder em jogos dialéticos, sem construir um sistema.

Que, aliás, Maine de Biran tenha um certo parentesco com Pascal, é o que podemos perceber quando lemos Ravaisson (1813-1900). Ligado tanto a Pascal quanto a Maine de Biran, apaixonado tanto pela arte grega quanto pela filosofia grega, Ravaisson nos faz admiravelmente compreender como a originalidade de cada filósofo francês não o impede de se religar a uma certa tradição, e como esta própria tradição reencontra a tradição clássica. Descartes, por exemplo, esforçou-se em vão para romper com a filosofia dos antigos: sua obra conserva as qualidades de ordem e de medida que foram características do pensamento grego. Ravaisson revelou este lado artístico e clássico do pensamento filosófico francês. Ele mesmo traçou os lineamentos de uma filosofia que mede a realidade das coisas segundo seu grau de beleza.

Não podemos pronunciar o nome de Ravaisson sem a ele associar o de Lachelier, um pensador cuja influência foi também considerável. Lachelier despertou a filosofia universitária num momento em que ela estava anestesiada pela doutrina fácil e amável de Victor Cousin (1792-1867). ${ }^{9}$ Sua tese sobre o fundamento da indução permanecerá clássica, como tudo o que traz a marca da perfeição. Sua doutrina, que invoca o kantismo, ultrapassa em realidade o idealismo de Kant e inaugura mesmo um realismo de um gênero particular, que poderia ser vinculado ao de Maine de Biran. Mestre incomparável, ele formou com seu pensamento várias gerações de mestres.

Da filosofia de Ravaisson, e mais particularmente de suas visões sobre o hábito, da filosofia de Auguste Comte também (enquanto afirma a irredu-

9 Não insistimos sobre a filosofia de Cousin pois ela foi sobretudo, um ecletismo. Houve entretanto, na Escola de Cousin, filósofos muito notáveis, tais como Saisset, Simon, Janet. É preciso coceder lugar a parte a Jouffroy (1796-1842) e a Vacherot (1809-1897). Como precursor de Cousin citemos Royer-Collard (1763-1845) 
tibilidade das ciências umas em relação às outras), poderíamos aproximar a teoria nova e profunda que Boutroux expõe em sua tese sobre "a contingência das leis da natureza". Por uma via bem diferente, pela análise das condições às quais está submetida a construção dos conceitos científicos, o grande matemático Henri Poincaré (1854-1912) chegou a conclusões do mesmo gênero: ele mostra o que há de relativo ao homem, de relativo às exigências e às preferências de nossa ciência, na rede de leis que nosso pensamento estende sobre o universo. Análoga é a doutrina de Milhaud. ${ }^{10} \mathrm{E}$ poderíamos classificar do mesmo lado Édouard Le Roy, se a obra deste filósofo não fosse animada, apesar de certas semelhanças exteriores, de um espírito diferente: sua crítica da ciência está ligada a visões pessoais, profundas, sobre a realidade em geral, sobre a moral e a religião. ${ }^{11}$

A idéia dominante de Liard foi manter frente a frente a metafísica e a ciência, como duas formas igualmente legítimas do pensamento. O mesmo cuidado existe em Fouillée (1838-1912). Psicólogo e sociólogo tanto quanto dialético, Fouillée desenvolveu uma teoria das idéias-força que é um racionalismo alargado. Não há qualquer questão, teórica ou prática, que este pensador brilhante não tenha abordado e sobre a qual ele não tenha apresentado visões interessantes e sugestivas. Ele teve em Guyau (1854-1888) um discípulo genial. Menos célebre que Nietzsche, Guyau havia sustentado, antes do filósofo alemão, em termos mais moderados e sob uma forma mais aceitável, que o ideal moral deve ser buscado na mais alta expansão possível da vida.

Deixamos de lado nesta enumeração rápida, dois pensadores de primeira ordem que não poderíamos vincular à tradição saída de Maine de Biran. Queremos falar de Renouvier e de Cournot. ${ }^{12}$

Saído do criticismo kantiano, que ele havia aliás profundamente modificado desde o início, Renouvier (1818-1903) dele se desligou pouco a pouco

10 Deixamos de lado, no presente estudo, os trabalhos relativos à análise e à crítica dos métodos científicos. A parte da França, aqui, ainda é considerável Citemos, entre muitos outros autores: o grande químico Berthelot, Jules e Paul Tannery, Lechalas, Couturat, Duhem, Rey, Perrin, Borel, Pierre Boutroux, L. Poincaré, Goblot. A obra de Lalande, como também as de Meyerson e de Brunschvicg, pertencem ao mesmo tempo à teoria das ciências e à filosofia geral. Diríamos o mesmo do belo livro de Hannequin sobre a teoria dos átomos. - Nos trabalhos de Le Dantec encontramos uma interpretação e uma extensão mecanicistas da ciência positiva. Não podemos tampouco falar da estética (Sully-Prudhomme, Séailles, Souriau, Dauriac, Bazaillas, Paulhan, Lalo, etc), nem da história da filosofia (Ravaisson, Cousin, Bouillier, Janet, Vacherot, Fouillée, Emile Boutroux, Delbos, Lévy-Brühl, Brochard, Espinas, Adam, Thamin, Halévy, Picavet, Faguet, X. Léon, G. Lyon, Delacroix, R. Berthelot, Hamelin, Basch, Berr, Rodier, Robin, Rivaud, Bréhier, etc).

11 A filosofia religiosa produziu, na França, trabalhos importantes. Lembremos apenas, para considerarmos os mais recentes, os nomes de Ollé-Laprune, de Blondel, de Laberthonnière, de Fonsegrive, de Wilbois, de H. Bois, de Segond, d'Auguste Sabatier, de Paul Sabatier, etc

12 Quantos outros metafísicos e psicólogos mereceriam ser estudados aqui! Citemos em particular, Évellin, Dunan, Paulhan, Weber. 
para chegar a conclusões que não são muito afastadas, quanto a letra, das do dogmatismo metafísico: ele afirma, em particular, a independência da pessoa humana; ele reintegra a liberdade no mundo. Mas ele renova a significação destas teses, aproximando-as dos dados da ciência positiva, e, sobretudo, fazendo-as preceder de uma crítica do entendimento humano. Tanto por sua moral, quanto por sua teoria da natureza e do homem, ele agiu consideravelmente sobre o pensamento de seu tempo. ${ }^{13}$

Conduzido à filosofia, ele também, pelo estudo das ciências, e em particular pelas matemáticas, Cournot (1801-1877) instituiu uma crítica de um gênero novo, que, diferente da crítica kantiana, trata ao mesmo tempo da forma e da matéria de nosso conhecimento, dos métodos e dos resultados. Sobre muitos pontos - notadamente sobre o acaso e a probabilidade - ele introduziu visões novas, penetrantes e profundas. É hora de colocar este pensador em seu verdadeiro lugar, - um dos primeiros, - entre os filósofos do século XIX.

Poderíamos agora, para concluir, dizer uma palavra sobre a empreitada tentada pelo autor de l'Évolution créatrice para conduzir a metafísica sobre o terreno da experiência e para constituir, fazendo apelo à ciência e à consciência, desenvolvendo a faculdade de intuição, uma filosofia capaz de fornecer, não mais somente teorias gerais, mas também explicações concretas de fatos particulares. A filosofia assim entendida é susceptível da mesma precisão que a ciência positiva. Como a ciência, ela poderá progredir sem cessar acrescentando uns aos outros os resultados adquiridos. Mas ela visará, além disto, - e é por isto que ela se distingue da ciência - ampliar cada vez mais os quadros do entendimento, devendo romper com um ou outro dentre eles, e dilatar indefinidamente o pensamento humano.

\section{II}

Passamos em revista um certo número de filósofos franceses, levando em conta, sobretudo sua diversidade, sua originalidade, o que eles trouxeram de novo e o que o mundo lhes deve. Vamos agora verificar se eles não apresentariam certos traços comuns, característicos do pensamento francês.

O traço que impressiona inicialmente, quando percorremos um de seus livros, é a simplicidade da forma. Se deixarmos de lado, na segunda metade do século XIX, um período de vinte ou trinta anos durante o qual, um pequeno número de pensadores, sofrendo uma influência estrangeira, aban-

13 Entre os filósofos que se vinculam a Renouvier, citemos Pillon, Dauriac e Hamelin. 
donou às vezes, a clareza tradicional, podemos dizer que a filosofia francesa foi sempre determinada pelo seguinte princípio: não há idéia filosófica, por mais profunda ou sutil que seja, que não possa e não deva exprimir-se na língua de todo mundo. Os filósofos franceses não escrevem para um círculo restrito de iniciados; eles se dirigem à humanidade em geral. Se, para medir a profundidade de seus pensamentos e para compreendê-la plenamente é preciso ser filósofo e sábio, todavia, não há homem cultivado que não esteja em estado de ler suas principais obras e de tirar delas algum proveito. Quando eles tiveram necessidade de novos meios de expressão, eles não os procuraram, como se fez em outros lugares, na criação de um vocabulário especial (operação que acaba por encerrar, em termos artificialmente compostos, idéias incompletamente digeridas), mas antes num conjunto engenhoso de palavras usuais, que dão a estas palavras novas nuances de sentido e permite-lhes traduzir as idéias mais sutis ou mais profundas. Assim se explica que um Descartes, um Pascal, um Rousseau, - para citar apenas estes, - tenham aumentado muito a força e a flexibilidade da língua francesa, seja tendo por objeto de sua análise mais propriamente o pensamento (Descartes), seja tendo também o sentimento (Pascal, Rousseau). É preciso, com efeito, ter levado até o fim a decomposição do que se tem no espírito para chegar a exprimir-se em termos simples. Mas, em graus diferentes, todos os filósofos franceses tiveram este dom de análise. A necessidade de resolver as idéias e mesmo os sentimentos em elementos claros e distintos, que encontram seus meios de expressão na língua comum, é característica da filosofia francesa desde suas origens.

Se agora passamos da forma ao fundo, eis o que notaremos inicialmente.

A filosofia francesa esteve sempre estreitamente ligada à ciência positiva. Em outros lugares, na Alemanha, por exemplo, tal filósofo pôde ser sábio, tal sábio pôde ser filósofo; mas o encontro das duas atitudes ou dos dois hábitos foi um fato excepcional e, por assim dizer, acidental. Se Leibniz foi ao mesmo tempo um grande filósofo e um grande matemático, vemos que o principal desenvolvimento da filosofia alemã, o que preenche a primeira metade do século XIX, se efetuou fora da ciência positiva. É da essência da filosofia francesa, ao contrário, apoiar-se sobre a ciência. Em Descartes, a união é tão íntima entre a filosofia e as matemáticas que é difícil dizer se sua geometria lhe foi sugerida por sua metafísica ou se sua metafísica é uma extensão de sua geometria. Pascal foi um profundo matemático, um físico original, antes de ser um filósofo. A filosofia francesa do século XVIII provém principalmente dos geômetras, dos naturalistas e dos médicos (d'Alembert, La Mettrie, Bonnet, Cabanis, etc). No século XIX, alguns dos maiores pensadores franceses, Auguste Comte, Cournot, Renouvier, etc, vieram à filosofia através das matemáticas; um deles, Henri Poincaré, foi um matemático de gênio. Claude Bernard, que nos deu a filosofia do méto- 
do experimental, foi um dos criadores da ciência fisiológica. Mesmo os filósofos franceses que se consagraram durante o último século à observação interior sentiram a necessidade de procurar fora deles, na fisiologia, na patologia mental, etc, alguma coisa que os assegurasse que eles não se entregavam a um simples jogo de idéias, a uma manipulação de conceitos abstratos: a tendência é já visível no grande iniciador do método de introspecção profunda, Maine de Biran. Em uma palavra, a união estreita da filosofia e da ciência é um fato tão constante, na França, que ele poderia ser suficiente para caracterizar e definir a filosofia francesa.

Um traço menos particular, mas que ainda impressiona, é o gosto dos filósofos franceses pela psicologia, sua inclinação para a observação interior. Certamente este traço não poderia mais bastar, como o precedente, para definir a tradição francesa, pois a atitude de sondar-se a si mesmo, de penetrar simpaticamente na alma do outro, foi sem dúvida tão propagada na Inglaterra e na América, por exemplo, quanto o foi na França. Mas, enquanto os grandes pensadores alemães (mesmo Leibniz, mesmo Kant) não tiveram, em todo caso não manifestaram muito, sentido psicológico, enquanto Schopenhauer (todo impregnado, aliás, da filosofia francesa do século XVIII) é talvez o único metafísico alemão que foi psicólogo, ao contrário não há grande filósofo francês que não se tenha revelado, eventualmente, sutil e penetrante observador da alma humana. Inútil relembrar os finos estudos psicológicos que encontramos em Descartes e em Malebranche, intimamente imbricados a suas especulações metafísicas. A visão de um Pascal era tão aguda quando ela se exercia nas regiões mal iluminadas da alma quanto nas ocasiões em que ela se dirigia para as coisas físicas, geométricas, filosóficas. Condillac foi um psicólogo tanto quanto um lógico. Que dizer então daqueles que abriram novos caminhos para a análise psicológica, como Rousseau ou Maine de Biran? Durante todo o século XVII e o XVIII, o pensamento francês, exercendo-se sobre a vida interior, preparou a psicologia puramente científica que devia ser obra do século XIX. Ninguém, aliás, contribuiu mais para fundar esta psicologia científica que um Moreau de Tours, um Charcot ou um Ribot. Observemos que o método destes psicólogos, - aquele que proporcionou à psicologia, em suma, suas mais importantes descobertas, não é senão uma extensão do método de observação interior. É sempre à consciência que ele faz apelo; apenas ele nota as indicações da consciência no doente, ao invés de ater-se ao homem de boa saúde.

Tais são os dois principais traços da filosofia francesa.

Compondo-se em conjunto, eles dão a esta filosofia sua fisionomia própria. É uma filosofia que considera de perto os contornos da realidade exterior, tal como o físico a representa, e de muito perto também os da realidade interior, tal como ela aparece ao psicólogo. Compondo-se conjuntamente, eles dão a esta filosofia sua fisionomia própria. É uma filosofia que apreende 
de perto os contornos da realidade exterior, tal como o físico a representa, e de muito perto também, os da realidade interior, tal como ela aparece ao psicólogo. Por isto mesmo ela freqüentemente tem aversão a tomar a forma de um sistema. Ela rejeita tanto o dogmatismo em excesso, quanto o criticismo radical; seu método é tão afastado do de um Hegel quanto do de um Kant. Isto não quer dizer que ela não seja capaz de edificar, quando quiser, alguma grande construção. Mas os filósofos franceses parecem ter tido geralmente este pensamento dissimulado que sistematizar é fácil, que é muito fácil ir até o fim de uma idéia, que a dificuldade está antes em parar a dedução onde é preciso, em modificar o curso como é preciso, graças ao aprofundamento das ciências particulares e ao contato incessantemente mantido com a realidade. Pascal disse que o "espírito de geômetra" não basta: o filósofo deve aí acrescentar o "espírito de finura". E Descartes, este grande metafísico, declarava haver consagrado poucas horas à metafísica, entendendo por isso, sem dúvida, que o trabalho de pura dedução ou de pura construção metafísica se efetua por si mesmo, por pouco que se tenha o espírito predisposto. - Alegar-se-á que, fazendo-se menos sistemática a filosofia desvia-se de seu objetivo, e que seu papel é precisamente unificar o real? - Mas a filosofia francesa jamais renunciou a esta unificação. Apenas ela não confia no procedimento que consiste em tomar uma ou outra idéia, e nela fazer entrar, por bem ou por mal, a totalidade das coisas. A esta idéia poder-se-á sempre opor uma outra, com a qual se construirá, segundo o mesmo método, um sistema diferente; os dois sistemas serão, aliás, igualmente sustentáveis, igualmente inverificáveis; de modo que a filosofia tornar-se-á um simples jogo, um torneio entre dialéticos. Notemos que uma idéia é um elemento de nossa inteligência, e que nossa própria inteligência é um elemento da realidade: como então uma idéia, que não é senão uma parte de uma parte abarcaria o Todo? A unificação das coisas somente poderá efetuar-se por uma operação muito mais difícil, longa, delicada: o pensamento humano, ao invés de restringir a realidade à dimensão de uma de suas idéias, deverá ele mesmo dilatar-se até coincidir com uma porção cada vez mais vasta da realidade. Mas será preciso para tanto o trabalho acumulado de muitos séculos. Enquanto isso, o papel de cada filósofo é extrair, do conjunto das coisas, uma visão que poderá ser definitiva sobre certos pontos, mas que será necessariamente provisória sobre outros. Teremos aí, se quisermos, uma espécie de sistema; mas o próprio princípio do sistema será flexível, indefinidamente extensível, ao invés de ser um princípio absoluto, como os que até agora produziram as construções metafísicas propriamente ditas. Tal é, nos parece, a idéia implícita da filosofia francesa. É uma idéia que não se tornou completamente consciente dela mesma, ou que se esforçou para formular-se apenas nestes últimos tempos. Mas, se ela não havia se manifestado anteriormente, foi justamente porque era natural 
ao espírito francês, espírito flexível e vivo, que não possui nada de mecânico ou de artificial, espírito eminentemente sociável também, que se opõe às construções individuais e vai instintivamente ao que é humano.

Assim, pelas duas ou três tendências que acabamos de indicar, se explica talvez o que houve de constantemente genial e de constantemente criador na filosofia francesa. Como sempre se impôs a falar a língua de todo mundo, ela não foi o privilégio de uma espécie de casta filosófica; ela permaneceu submissa ao controle de todos; ela jamais rompeu com o senso comum. Praticada por homens que foram psicólogos, biólogos, físicos, matemáticos, ela se manteve continuamente em contato com a ciência tanto quanto com a vida. Este contato permanente com a vida, com a ciência, com o senso comum, a fecundou incessantemente ao mesmo tempo que ele a inpedia de perder tempo com ela mesma, de recompor artificialmente as coisas com abstrações. Mas, se a filosofia francesa pôde se revificar indefinidamente assim, utilizando todas as manifestações do espírito francês, isto não ocorreu porque estas mesmas manifestações tendiam a adquirir a forma filosófica? Bem raros, na França, são os sábios, os escritores, os artistas e mesmo os artesãos que se absorvem na materialidade do que fazem, que não procuram extrair - seja com inabilidade, seja com alguma ingenuidade - a filosofia de sua ciência, de sua arte ou de sua profissão. A necessidade de filosofar é universal: ela tende a orientar toda discussão, mesmo de negócios, para o terreno das idéias e dos princípios. Ela traduz provavelmente a aspiração mais profunda da alma francesa, que vai direto ao que é geral e, daí, ao que é generoso. Neste sentido, o espírito francês se identifica com espírito filosófico. 